\title{
Overview: referrals for genetic evaluation from child psychiatrists
}

\author{
Katharine R. Press ${ }^{1 *}$, Laura Wieczorek ${ }^{2}$, Julie Hoover-Fong ${ }^{3}$, Joann Bodurtha ${ }^{3}$ and Lynn Taylor ${ }^{4}$
}

\begin{abstract}
A growing multitude of known genetic diagnoses can result in presentation to child psychiatry. For numerous reasons, it is important to identify a genetic etiology in child psychiatry patients when it is present. Genetic diagnoses can guide treatment and enable access to specialized clinics and appropriate screening measures. They can also allow for genetic counseling for the patient and family. A better understanding of etiology with a named diagnosis can itself be of great value to many patients and families; prognostic information can be empowering. Since patients with genetic conditions may present to psychiatric care in diverse ways, child psychiatrists must decide who to refer for genetic evaluation. Here we create a table to provide a framework of concerning/notable history and exam features that a practicing child psychiatrist may encounter that should prompt one to consider whether a larger, unifying genetic diagnosis is at hand. We hope this framework will facilitate referral of child psychiatry patients to genetics so that more patients can benefit from an appropriate diagnosis.
\end{abstract}

Keywords: Diagnosis, Genetics, Child psychiatry

\section{Background}

A growing multitude of known genetic diagnoses can result in presentation to child psychiatry. The prevalence of genetic diagnoses among child psychiatry patients is best studied for autism, where $10-20 \%$ of cases have a diagnosable genetic cause [e.g. Fragile X (FXS)] [1-6]. There is little information about the prevalence of genetic conditions in child psychiatry patients more generally. There are a large number of different genetic conditions that may lead to psychiatric presentation in a child. A December 2015 search of the Online Mendelian Inheritance in Man database (OMIM.org ${ }^{\circledR}$ ), a catalog of genetic conditions, reveals 42 genetic etiologic associations for both psychiatric symptoms and autism. As genetic understanding continues to progress, the overlap with child psychiatry grows and it becomes increasingly important for child psychiatrists to recognize signs of a possible underlying genetic diagnoses [7].

\footnotetext{
*Correspondence: kpress2@jhmi.edu

1733 North Broadway, Suite 137-Office of Student Affairs,

Edward D. Miller Research Building, Baltimore, MD 21205, USA

Full list of author information is available at the end of the article
}

In some instances, a genetic condition may have a typical psychiatric presentation and psychiatric symptoms may appear isolated. In such cases, presentation may be indistinguishable from that of a typical psychiatric patient whose disease is polygenic and multifactorial and genetic diagnosis is more difficult [8]. However, in many cases a genetic etiology may be suggested by features of history or physical exam. If child psychiatrists are aware of red flags signifying possible genetic condition, more patients can be appropriately diagnosed.

This article addresses two questions: Why is it important to diagnose genetic conditions in child psychiatry patients? What should prompt a child psychiatrist to request a genetic consult for a patient?

\section{Main text}

\section{Benefits of diagnosing genetic conditions}

Identifying a genetic etiology in child psychiatry patients has many benefits [9]. Diagnosis of specific genetic conditions can guide treatment and allow access to specialized healthcare. For example, depression may herald Wilson disease, which can be effectively treated with chelators [10]. In metabolic disorders with psychiatric symptoms, a diagnosis can allow for appropriate management 
to avoid metabolic decompensations, which worsen both psychiatric and somatic symptoms [8]. In children with FXS, hyperactivity responds particularly well to methylphenidate. Hyperactivity is more responsive to methylphenidate as part of FXS versus part of autism spectrum disorder or intellectual disability, or possibly even nonspecific ADHD [3]. When diagnosed, these patients can be put directly on methylphenidate and avoid many medication trials, which carry associated risks. Furthermore, because psychiatric symptoms may arise years before more specific organic signs, certain treatments may be more effective at the 'psychiatric stage' before occurrence of irreversible lesions. This is particularly true for metabolic disorders [11]. Genetic diagnosis also enables access to specialized clinics with greater understanding of and experience with these complex presentations [12]. There are a growing number of condition-specific and neurogenetic clinics that may be very beneficial to patients. Because wait times to appointments can be challenging, other consultation strategies (e.g. telehealth) may be considered.

Additionally, some genetic conditions are associated with known medical complications and may require routine screening or further medical work-up. For example, a patient presenting with autism spectrum disorder and macrocephaly who is found to have a PTEN mutation can then be enrolled in a cancer screening protocol. Further, diagnosis can allow for appropriate genetic counseling for the patient and family $[12,13]$.

Finally, a better understanding of etiology with a named diagnosis may itself be of great value to many. Most individuals would rather know they have a serious disease than continue without a diagnosis [14]. Diagnosis allows for improved understanding, educational planning, and social support, and peer networking $[15,16]$. Prognostic information can be empowering.

\section{Indications for genetic consultation}

It is not practical to conduct a genetic workup on all patients, so child psychiatrists must decide whom to refer for genetic evaluation [1]. Child psychiatrists are in an important position to diagnose genetic conditions, as they often see children for whom a diagnosis has been elusive, who have unusual presentations, or who have been difficult to treat.

Patients with genetic conditions may present to psychiatric care in diverse ways. Table 1 shows genetic conditions that may in rare cases account for typical child psychiatry presentations. Psychiatric symptoms may be apparently isolated, making genetic diagnosis difficult. However, often a careful history and physical provides hints to a genetic diagnosis.

Some unusual psychiatric presentations or behaviors may suggest a particular genetic etiology. Skin picking may occur in Prader-Willi syndrome [25] while severe disruptions of sleep and nail pulling suggest SmithMagenis syndrome [26]. In many cases, non-psychiatric features of the history or exam will provide clues to genetic etiology.

The purpose of Table 2 is to present a framework of notable history and exam features that should prompt a child psychiatrist to consider whether there is a larger, unifying genetic diagnosis at hand. All of these features are recognized as markers in pediatric genetic practice, however here the goal is to isolate the flags most likely to present in a child psychiatry practice [27]. This table is just a starting point and should not be considered exhaustive.

If one or more of these red flags are present, a child psychiatrist should consider requesting a genetic consultation. Whenever possible, genetic tests should be ordered in conjunction with a genetic team. On a practical level, determining which genetic tests to order can be confusing and outside the usual practice of most child psychiatrists. Even more important, many child psychiatrists are not comfortable explaining the intricacies of genetic testing and lack the infrastructure to deal with ramifications of positive results [28]. Informed consent must include discussion of the risks of genetic testing, which include harms associated with

\section{Table 1 Genetic syndromes may in rare cases manifest in more general child psychiatry presentations}

\begin{tabular}{ll}
\hline Psychiatric presentation & Example of genetic syndrome that may result in this presentation \\
\hline Anxiety & $22 q 11$ deletion [17], Fragile X syndrome [18], Williams syndrome [19] \\
Acute psychosis & Adrenoleukodystrophy [20], Porphyria [21], Niemann-Pick [21], 22q11 deletion [17] \\
Conduct disorder/poor judgment/anger & Monoamine oxidase A deficiency [22] \\
Hyperactivity & Turner syndrome [23], Fragile X syndrome [3] \\
Depression & Wilson disease [24] \\
\hline
\end{tabular}




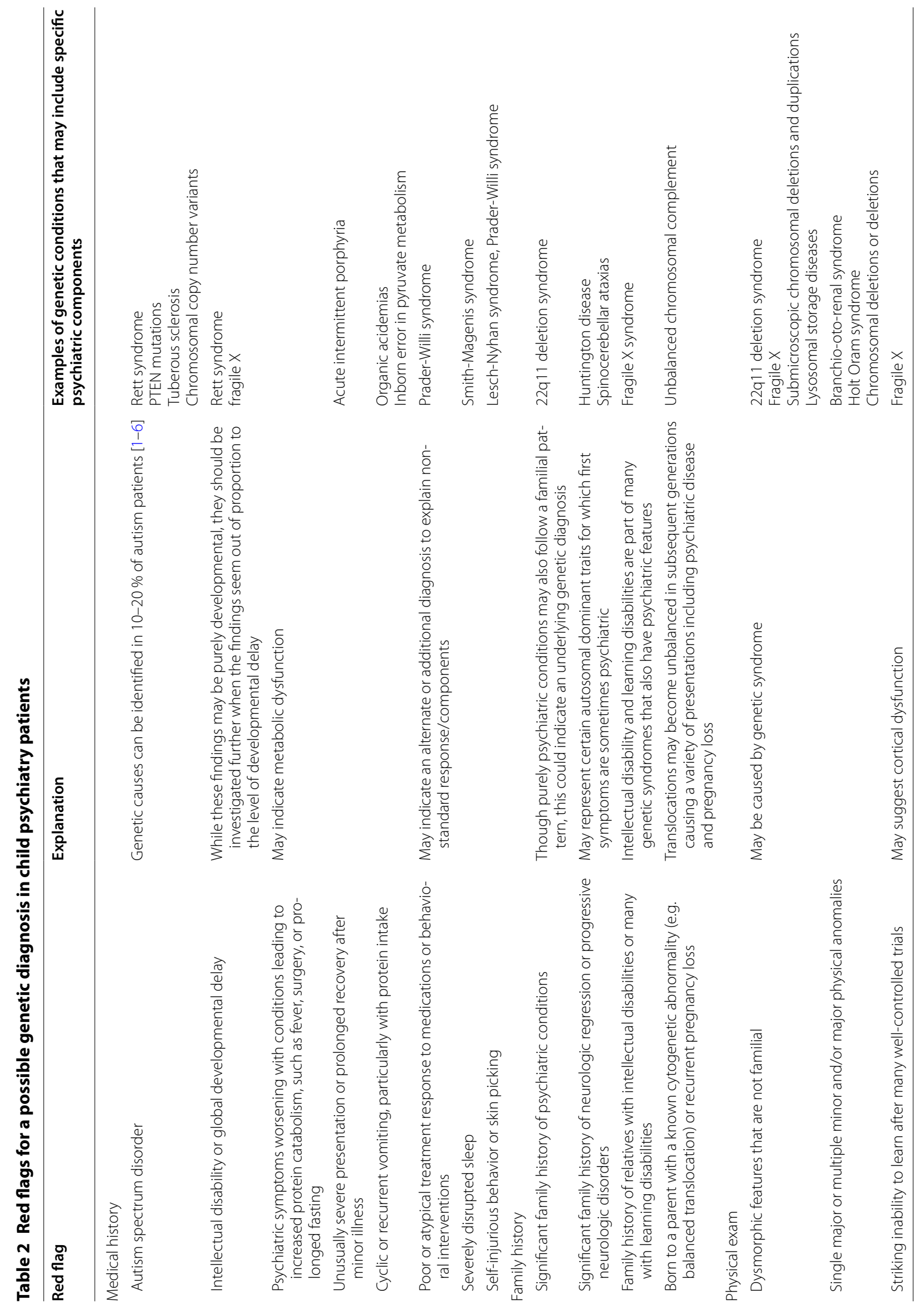




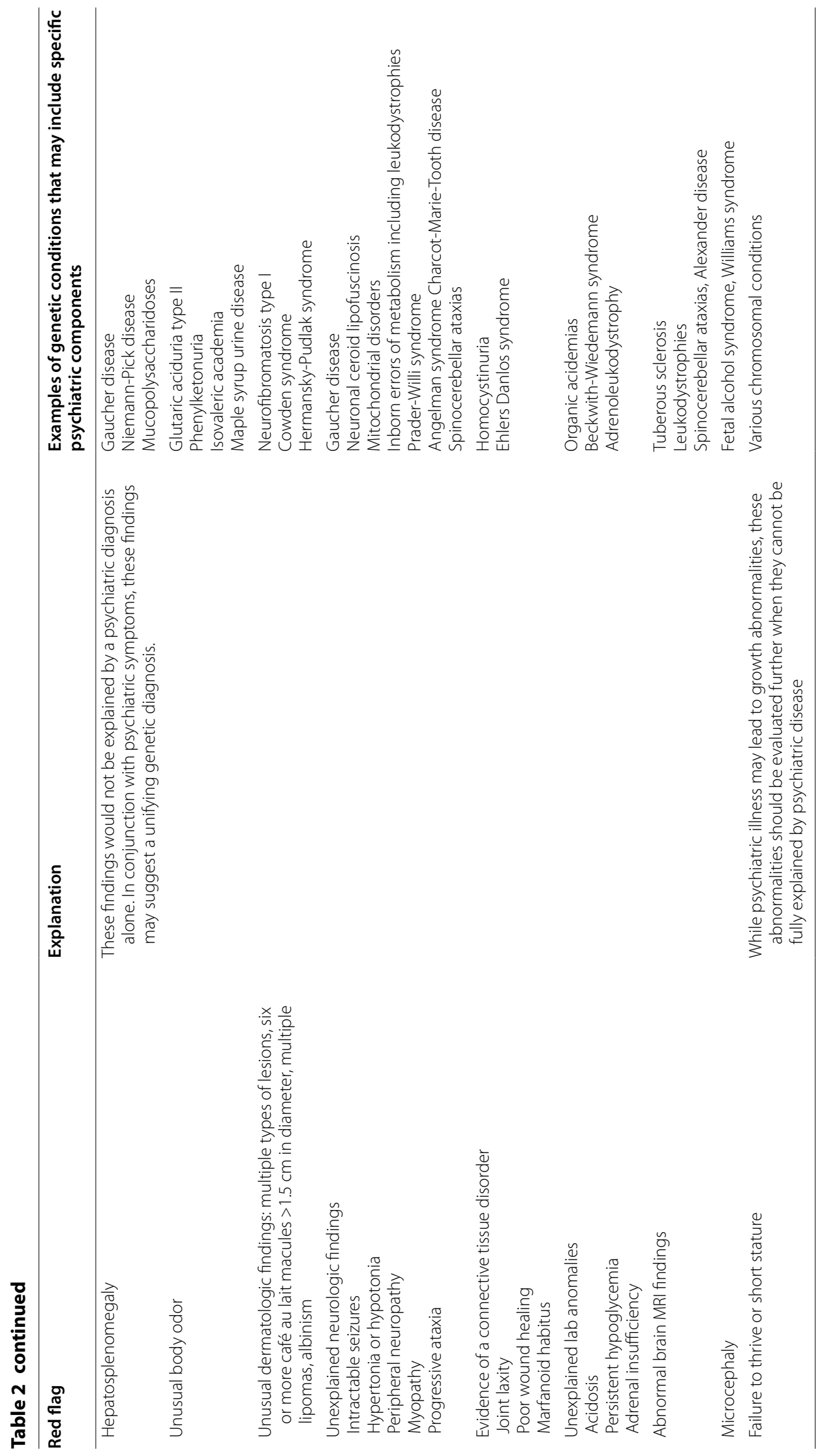


resultant treatments and incidental findings that can be life changing or psychologically disruptive [29]. There may be particular cases in which a child psychiatrist has experience with or training relevant to a certain genetic test and feels comfortable ordering this test, so this remains an individual call. However, in most cases it is best to involve a genetic team and employ their associated infrastructure. It is our hope that this table will help child psychiatrists communicate with genetic teams by allowing them to pinpoint the red flags that led them to consider a genetic etiology.

\section{Conclusions}

It is important to identify a genetic etiology in child psychiatry patients when it is present, as it has implications for treatment and counseling. Patients with genetic conditions may have unusual psychiatric symptoms or other abnormal history and physical findings. Here we present a table of red flags that a practicing child psychiatrist may identify, which could indicate an underlying genetic diagnosis. We hope this table will inspire child psychiatrists to think about genetic possibilities in their patient populations and make referrals for genetic evaluation when appropriate. Future work will be needed to validate this table in practice. However, being aware of these the flags has immediate utility in the clinical practice of child psychiatrists. To highlight how simple practice changes may have a big impact for diagnosing conditions, we provide a short list of tips and resources for making a genetic diagnosis in child psychiatry (Table 3). We hope that this commentary will encourage child psychiatrists to think about their growing overlap with the field of genetics. Recognition of the importance of genetic diagnoses in child psychiatry patients may stimulate more research into the prevalence of genetic disease, effective methods of screening and diagnosis, and strategies for treatment and management for these patients.

\section{Table 3 Short list of tips and resources for making genetic diagnoses in child psychiatry}

1. Take a family history

2. Measure and plot head circumference percentiles

3. Inspect the skin

4. Take note of dysmorphic features

5. Know your genetics referral colleagues

6. Short list of genetic resources

GeneReviews ${ }^{\circledR}:$ http://www.genereviews.org/

Online Mendelian Inheritance in Man (OMIM) ${ }^{\circledR}$ : http://www.omim. org/

Genetics Home Reference: http://ghr.nlm.nih.gov/

\section{Authors' contributions}

All authors have substantially contributed to the manuscript. All authors read and approved the final manuscript.

\section{Author details}

1733 North Broadway, Suite 137-Office of Student Affairs, Edward D. Miller Research Building, Baltimore, MD 21205, USA. ${ }^{2}$ Bloomberg Children's Center, 12th Floor, Room 12316, 1800 Orleans Street, Baltimore, MD 21287, USA. ${ }^{3}$ Blalock 1008 Medical Genetics, 600 North Wolfe Street, Baltimore, MD 21287, USA. ${ }^{4}$ Bloomberg Children's Center, 12th Floor, Room 12352, 1800 Orleans Street, Baltimore, MD 21287, USA.

\section{Competing interests}

The authors declare that they have no competing interests.

Received: 5 August 2015 Accepted: 22 February 2016

Published online: 28 March 2016

\section{References}

1. Schiff M, Benoist JF, Aissaoui S, Boespflug-Tanguy O, Mouren MC, de Baulny HO, Delorme R. Should metabolic diseases be systematically screened in nonsyndromic autism spectrum disorders? PLoS One. 2011;6(7):e21932.

2. Buxbaum JD, Cai G, Chaste P, Nygren G, Goldsmith J, Reichert J, Anckarsater H, Rastam M, Smith CJ, Silverman JM, Hollander E, Leboyer M, Gillberg C, Verloes A, Betancur C. Mutation screening of the PTEN gene in patients with autism spectrum disorders and macrocephaly. Am J Med Genet B Neuropsychiatr Genet. 2007;144B(4):484-91.

3. Roberts JE, Miranda M, Boccia M, Janes H, Tonnsen BL, Hatton DD. Treatment effects of stimulant medication in young boys with fragile $X$ syndrome. J Neurodev Disord. 2011;3(3):175-84.

4. Cochran DM, Dvir Y, Frazier JA. "Autism-plus" spectrum disorders: intersection with psychosis and the schizophrenia spectrum. Child Adolesc Psychiatr Clin N Am. 2013;22(4):609-27.

5. Miller DT, Adam MP, Aradhya S, et al. Consensus statement: chromosomal microarray is a first-tier clinical diagnostic test for individuals with developmental disabilities or congenital anomalies. Am J Hum Genet. 2014;86(5):749-64.

6. Shen J, Lincoln S, Miller DT. Advances in genetic discovery and implications for counseling of patients and families with autism spectrum disorders. Curr Genet Med Rep. 2014;2(3):124-34.

7. Hyman SE. The genetics of mental illness: implications for practice. Bull World Health Organ. 2000;78(4):455-63.

8. Sedel F, Baumann N, Turpin JC, Lyon-Caen O, Saudubray JM, Cohen D. Psychiatric manifestations revealing inborn errors of metabolism in adolescents and adults. J Inherit Metab Dis. 2007;30(5):631-41.

9. ACMG Board of Directors. Clinical utility of genetic and genomic services: a position statement of the American College of Medical Genetics and Genomics. Genet Med. 2015;17(6):505-7.

10. Zimbrean PC, Schilsky ML. The spectrum of psychiatric symptoms in Wilson's disease: treatment and prognostic considerations. Am J Psychiatry. 2015;172(11):1068-72

11. Demily C, Sedel F. Psychiatric manifestations of treatable hereditary metabolic disorders in adults. Ann Gen Psychiatry. 2014;13:27.

12. Schaefer GB, Mendelsohn NJ, Professional Practice and Guidelines Committee: Clinical genetics evaluation in identifying the etiology of autism spectrum disorders: 2013 guideline revisions. Genet Med. 2013;15(5):399-407.

13. Butler MG, Dasouki MJ, Zhou XP, Talebizadeh Z, Brown M, Takahashi TN, Miles JH, Wang CH, Stratton R, Pilarski R, Eng C. Subset of individuals with autism spectrum disorders and extreme macrocephaly associated with germline PTEN tumour suppressor gene mutations. J Med Genet. 2005;42(4):318-21.

14. GahI WA, Tifft CJ. The NIH undiagnosed diseases program: lessons learned. JAMA. 2011;305(18):1904-5.

15. Saul R. Medical genetics in pediatric practice. 1st ed. American Academy of Pediatrics; 2013.

16. Reiff M, Giarelli E, Bernhardt BA, Easley E, Spinner NB, Sankar PL, Mulchandani S. Parents' perceptions of the usefulness of chromosomal microarray 
analysis for children with autism spectrum disorders. J Autism Dev Disord. 2015;45(10):3262-75.

17. Stephenson DD, Beaton EA, Weems CF, Angkustsiri K, Simon TJ. Identifying patterns of anxiety and depression in children with chromosome 22q11.2 deletion syndrome: comorbidity predicts behavioral difficulties and impaired functional communications. Behav Brain Res. 2015;276:190-8.

18. Saldarriaga W, Tassone F, Gonzalez-Teshima LY, Forero-Forero JV, Ayala-Zapata S, Hagerman R. Fragile X syndrome. Colomb Med (Cali). 2014;45(4):190-8.

19. Ng R, Fillet P, DeWitt M, Heyman GD, Bellugi U. Reasoning about trust among individuals with Williams syndrome. Am J Intellect Dev Disabil. 2015;120(6):527-41

20. Ramos-Rios R, Berdullas J, Arauxo A, Santos-Garcia D. Schizophreniform psychosis at onset of adrenoleukodystrophy. CNS Spectr. 2009;14(12):711-2.

21. Bonnot O, Herrera PM, Tordjman S, Walterfang M. Secondary psychosis induced by metabolic disorders. Front Neurosci. 2015;9:177.

22. Bortolato M, Shih JC. Behavioral outcomes of monoamine oxidase deficiency: preclinical and clinical evidence. Int Rev Neurobiol. 2011;100:13-42.
23. Russell HF, Wallis D, Mazzocco MM, Moshang T, Zackai E, Zinn AR, Ross JL, Muenke M. Increased prevalence of ADHD in Turner syndrome with no evidence of imprinting effects. J Pediatr Psychol. 2006;31 (9):945-55.

24. Alam ST, Rahman MM, Islam KA, Ferdouse Z. Neurologic manifestations, diagnosis and management of Wilson's disease in children —an update. Mymensingh Med J. 2014;23(1):195-203.

25. Rice LJ, Einfeld SL. Cognitive and behavioural aspects of Prader-Willi syndrome. Curr Opin Psychiatry. 2015;28(2):102-6.

26. Finucane B, Dirrigl KH, Simon EW. Characterization of self-injurious behaviors in children and adults with Smith-Magenis syndrome. Am J Ment Retard. 2001;106(1):52-8.

27. Pletcher BA, Toriello HV, Noblin SJ, Seaver LH, Driscoll DA, Bennett RL, Gross SJ. Indications for genetic referral: a guide for healthcare providers. Genet Med. 2007;9(6):385-9.

28. Cohen J, Hoon A, Wilms Floet AM. Providing family guidance in rapidly shifting sand: informed consent for genetic testing. Dev Med Child Neurol. 2013:55(8):766-8.

29. Ross LF, Saal HM, David KL, Anderson RR, American Academy of Pediatrics, American College of Medical Genetics and Genomic: Technical report: Ethical and policy issues in genetic testing and screening of children. Genet Med. 2013;15(3):234-45.

\section{Submit your next manuscript to BioMed Central and we will help you at every step:}

- We accept pre-submission inquiries

- Our selector tool helps you to find the most relevant journal

- We provide round the clock customer support

- Convenient online submission

- Thorough peer review

- Inclusion in PubMed and all major indexing services

- Maximum visibility for your research

Submit your manuscript at www.biomedcentral.com/submit
() Biomed Central 